\title{
BMJ Open Are healthcare aides underused in long- term care? A cross-sectional study on continuing care facilities in Canada
}

\author{
Mubashir A Arain, Siegrid Deutschlander, Paola Charland
}

To cite: Arain MA, Deutschlander S, Charland $\mathrm{P}$. Are healthcare aides underused in long-term care? A cross-sectional study on continuing care facilities in Canada. BMJ Open 2017;7:e015521. doi:10.1136/ bmjopen-2016-015521

- Prepublication history and additional material are available. To view please visit the journal (http://dx.doi.org/10.1136/ bmjopen-2016-015521)

Received 9 December 2016 Revised 28 February 2017 Accepted 8 March 2017

CrossMark

Workforce Research \& Evaluation, Alberta Health Services, Calgary, Alberta, Canada

Correspondence to Dr. Mubashir A Arain; mubashiraslam.arain@ahs.ca

\begin{abstract}
Objectives Over the last 10 years, appropriate workforce utilisation has been an important discussion among healthcare practitioners and policy-makers. The role of healthcare aides (HCAs) has also expanded to improve their utilisation. This evolving role of HCAs in Canada has prompted calls for standardised training, education and scope of practice for HCAs. The purpose of this research was to examine the differences in HCAs training and utilisation in continuing care facilities.

Design From June 2014 to July 2015, we conducted a mixed-method study on HCA utilisation in continuing care. This paper presents findings gathered solely from the prospective cross-sectional survey of continuing care facilities (long-term care (LTC) and supportive living (SL)) on HCA utilisation.
\end{abstract}

Setting and participants We conducted this study in a Western Canadian province. The managers of the continuing care facilities (SL and LTC) were eligible to participate in the survey.

Primary outcome measures The pattern of HCAs involvement in medication assistance and other care activities in SL and LTC facilities.

Results We received 130 completed surveys (LTC=64 and $\mathrm{SL}=52$ ). Our findings showed that approximately $81 \%$ of HCAs were fully certified. We found variations in how HCAs were used in SL and LTC facilities. Overall, HCAs in SL were more likely to be involved in medication management such as assisting with inhaled medication and oral medication delivery. A significantly larger proportion of survey respondents from SL facilities reported that medication assistance training was mandatory for their HCAs (86\%) compared with the LTC facilities $(50 \%)$ ( $p$ value $<0.01$ )

Conclusion The utilisation of HCAs varies widely between SL and LTC facilities. HCAs in SL facilities may be considered better used according to their required educational training and competencies. Expanding the role of HCAs in LTC facilities may lead to a cost-effective and more efficient utilisation of workforce in continuing care facilities.

\section{INTRODUCTION}

Over the last 10 years, appropriate workforce utilisation has been an important topic for discussion among practitioners as well as decision and policy-makers in Canada. Healthcare systems have encountered
Strengths and limitations of this study

- This study provides valuable information about the variations in utilising healthcare aides (HCAs) in different types of continuing care facilities.

- The findings may be relevant to others looking to standardise the utilisation of HCAs in continuing care settings.

- The advisory committee of the study included a wide range of stakeholders (from continuing care facilities and government health agencies) who helped us in identifying potential issues in the continuing care workforce.

- The $41 \%$ response rate in the survey was appropriate for this particular population. However, our results might misrepresent HCA utilisation at the non-responding sites.

high demands, rising costs and scarcity of healthcare resources including workforce shortages. $^{2}$ Workforce utilisation is crucial to effective delivery, referring to the organisation and deployment of regulated and unregulated healthcare providers while optimising their collective ability to work to full scope of practice in patient care. ${ }^{3}$ Recent studies have highlighted the importance of mapping the scope of practice for healthcare aides (HCAs) in continuing care. ${ }^{4-7}$

HCAs are unregulated direct care providers also known as personal care attendants, support workers, resident care workers, nursing aides and nursing assistants. ${ }^{8}$ Unregulated means that they do not need to get a licence from a regulatory authority to work in their field. In Canada, HCAs provide up to $80 \%$ of direct care to seniors in care homes. ${ }^{9}$ HCAs provide physical and emotional support for clients with medical conditions or major functional limitations under the supervision of regulated nursing staff or other health professionals. HCAs are essential elements for improving care in continuing care facilities. ${ }^{10}$ The range of care depends on the patient population, care setting, knowledge and skills of individual HCAs, legislation 
and policy. In Canada, there is no national education standard for care aides to enter practice, and provincial variations in educational standards are common across the country. ${ }^{9}$ In Alberta, HCAs have a competency profile guiding their practice in healthcare. The government also aimed to standardise curriculum for HCAs by developing the Healthcare Aide Alberta Government Curriculum. This curriculum covers 40 competencies which are taught in 37 modules in educational institutions in Alberta. ${ }^{11}$ Despite the standardised curriculum and HCA competency profile, research shows that HCAs are not used optimally in Alberta's continuing care system. ${ }^{6}$ In addition to HCAs' competency profile, several individual and contextual factors play an important role in best-utilising HCAs in continuing care facilities. ${ }^{12}$ Involving HCAs in more skilled work such as medication assistance could help enhance their sense of personal accomplishment and importance to the organisation. ${ }^{12}$ Feelings of personal accomplishment also increase job satisfaction which results in improved quality of care and resident quality of life. ${ }^{13} 14$

In Alberta, HCAs are a valued and major component of the workforce in all three subsectors of continuing care including home care, supportive living (SL) and long-term care (LTC). Home care is for people who live in their independent accommodation and need some healthcare support at home. SL and LTC are facility-based services for seniors. SL facilities provide living accommodation services to seniors and address health and personal care needs of residents; HCAs primarily provide support, and licensed practical nurses (LPNs) are also onsite 24/7 at many sites. LTC facilities are available for individuals who can no longer live independently and require $24 / 7$ care. $^{15}$ In an effort

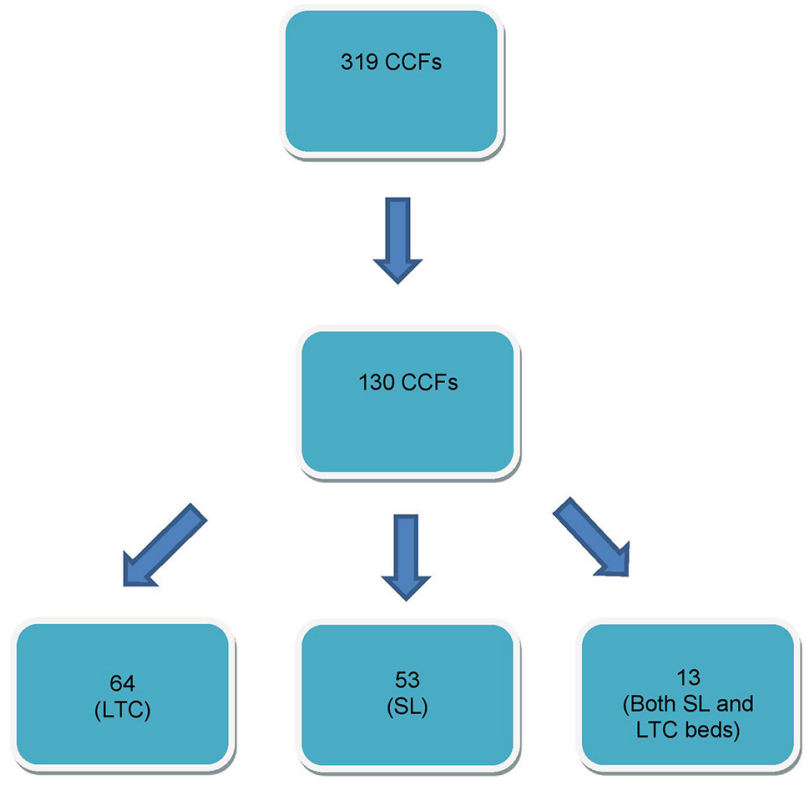

Figure 1 Flow diagram showing continuing care facilities (CCFs) participation in the survey. SL, supportive living; LTC, long-term care. to investigate how HCA utilisation differs, the authors conducted a mixed-method study to examine the utilisation of HCAs in different continuing care settings including SL and LTC facilities. The methods included a survey of continuing care facilities, interviews with staff and the use of secondary data on medication errors. Findings from interviews will be presented in a separate manuscript. This paper focuses solely on findings from the survey examining the training and utilisation of HCAs in SL and LTC. Our research question was focused on determining if HCAs have different roles and responsibilities in different depending on the continuing care facilities. We hypothesised that HCA utilisation differs significantly between SL and LTC facilities.

\section{METHODS}

We conducted this cross-sectional study on SL and LTC facilities from June 2014 to July 2015 in Alberta. The survey captured information on site context, staffing, HCA utilisation and service delivery. Surveys were sent to leadership at LTC and SL facilities by email or fax. The respondents were administrative (managerial) staff. All private and public LTC or SL facilities in Alberta were eligible to participate in the survey. The provincial Seniors Health Executive Directors identified the list of continuing care facilities. In total, the list included 319 continuing care facilities that were eligible to be included in this study.

The authors developed the survey tool (questionnaire) with feedback from stakeholders through the advisory committee to minimise reporting bias. The advisory committee was established for the project consisting of members from continuing care facilities and government health agencies. In the survey, the managers or leads of the facilities provided information about residents population needs, HCAs roles and responsibilities, educational backgrounds, required educational/training needs and safety concerns for patients in medication assistance (see the questionnaire in online supplementary file). The survey also included facility information on the type of services they provided, staffing, HCAs' utilisation and their perceptions about whether HCAs were optimally used. The questionnaire included three parts: (1) background information on setting and staff, (2) HCA responsibilities and (3) service delivery and resident care.

We entered and analysed data in SPSS version 19. We checked data for inconsistencies during the process of data cleaning. We made following corrections in the data set: five survey respondents did not provide an answer on whether they consider their HCAs fully used but they provided reasons for not considering them as fully used; we noted their response as 'do not consider their HCAs as fully used'. Two survey respondents wrote 'All' in the question about the number of certified HCAs; we corrected their response by entering the total number of HCAs at their facilities. We excluded 13 survey respondents from 
the comparative analysis who mentioned that their facilities include both SL and LTC beds.

We summarised and presented the information about continuing care facilities using descriptive statistics (mean with SD for normally distributed data and median with
IQR for skewed data). We also compared the utilisation of HCAs between SL and LTC facilities using a two-sided t-test for continuous variables and $\chi^{2}$ test for categorical variables at $95 \%$ confidence level; $p$ value $<0.05$ was considered as significant.

\begin{tabular}{|c|c|c|}
\hline Variables & Number & Median (range) \\
\hline \multicolumn{3}{|l|}{ No of beds, average (SD) } \\
\hline Long-term care & $103.1(82.9)$ & $80(8-414)$ \\
\hline Supportive living & $61.5(55.7)$ & $48(8-325)$ \\
\hline \multicolumn{3}{|l|}{ Site ownership } \\
\hline Private not for profit & 35 & $27.8^{*}$ \\
\hline Private for profit & 45 & $35.7^{\star}$ \\
\hline Publicly owned and operated & 46 & $36.5^{*}$ \\
\hline No of HCAs, average (SD) & $60(57.9)$ & $41(3-384)$ \\
\hline Full-time & $16.1(19.5)$ & $9.5(0-104)$ \\
\hline Part-time & $28.1(36.3)$ & $15(0-242)$ \\
\hline Casual & $14.9(17.8)$ & $10(0-137)$ \\
\hline \multicolumn{3}{|l|}{ Nursing staff, average FTEs (SD) } \\
\hline Registered nurses & $5.0(10.1)$ & $4(0-103)$ \\
\hline Registered psychiatric nurses & $0.1(0.4)$ & $0(0-2)$ \\
\hline Licensed practical nurses & $6.4(8.2)$ & $4(0-56)$ \\
\hline \multicolumn{3}{|l|}{ Managerial staff, average FTEs (SD) } \\
\hline Care manager & $1.3(2.6)$ & $1(0-26)$ \\
\hline Administrator/Director of care & $0.7(0.7)$ & $1(0-3)$ \\
\hline Clinical educator & $0.4(0.6)$ & $0(0-3)$ \\
\hline Nurse practitioner & $0.1(0.2)$ & $0(0-2)$ \\
\hline Care coordinator & $0.1(0.7)$ & $0(0-5)$ \\
\hline \multicolumn{3}{|l|}{ Allied health staff, average FTEs (SD) } \\
\hline Dietitian/nutritionist & $0.2(0.4)$ & $0(0-2)$ \\
\hline Occupational therapist & $0.5(0.8)$ & $0(0-4)$ \\
\hline Pharmacist & $0.1(0.4)$ & $0(0-2)$ \\
\hline Pharmacy technician & $0.1(0.3)$ & $0(0-2)$ \\
\hline Physiotherapist & $0.2(0.5)$ & $0(0-3)$ \\
\hline Psychologist & None & None \\
\hline Recreational therapist & $0.7(0.7)$ & $1(0-3)$ \\
\hline Speech and language pathologist & $0.1(0.1)$ & $0(0-1)$ \\
\hline Social worker & $0.3(0.6)$ & $0(0-4)$ \\
\hline Recreational therapy aide/assistant & $1.5(1.4)$ & $0(0-6)$ \\
\hline Occupational therapy aide/assistant & $0.9(1.2)$ & $0(0-5)$ \\
\hline \multicolumn{3}{|l|}{ Other staff/volunteers, average FTEs (SD) } \\
\hline Housekeeping & $3.0(3.8)$ & $2(0-18)$ \\
\hline Food services & $5.8(7.1)$ & $3(0-34)$ \\
\hline Maintenance/physical plant services & $1.2(1.5)$ & $1(0-12)$ \\
\hline Hospitality (laundry) & $0.8(1.4)$ & $0(0-6)$ \\
\hline Volunteers & $9.6(32.1)$ & $0(0-242)$ \\
\hline
\end{tabular}

*Values are expressed in percentages.

FTEs, full-time equivalents; HCAs, healthcare aides. 
Ethical approval for the study was obtained from the University of Calgary Research Ethics Board (REB 14-0377). The first page of the survey included information to inform participants about the purpose of the survey and their right to refuse participation.

\section{RESULTS}

We received 130 completed surveys out of 319 questionnaires resulting in a response rate of $41 \%$. Around $49 \%$ of these were from LTC facilities, $41 \%$ from SL and $10 \%$ from sites that housed both SL and LTC residents (figure 1).

The survey data confirmed that HCAs comprise the majority of the workforce in continuing care with an average of 60 HCAs per site (table 1). They included fulltime, part-time and casual positions. Other nursing staff comprised on average 6 full-time equivalents (FTEs) for LPNs and 5 FTEs for registered nurses (RNs) per site. Among the allied health staff, we found higher average FTEs for recreational therapy aide/assistants (1.5 FTEs) and occupational therapy/assistants (0.9 FTE) than other allied health staff (table 1).

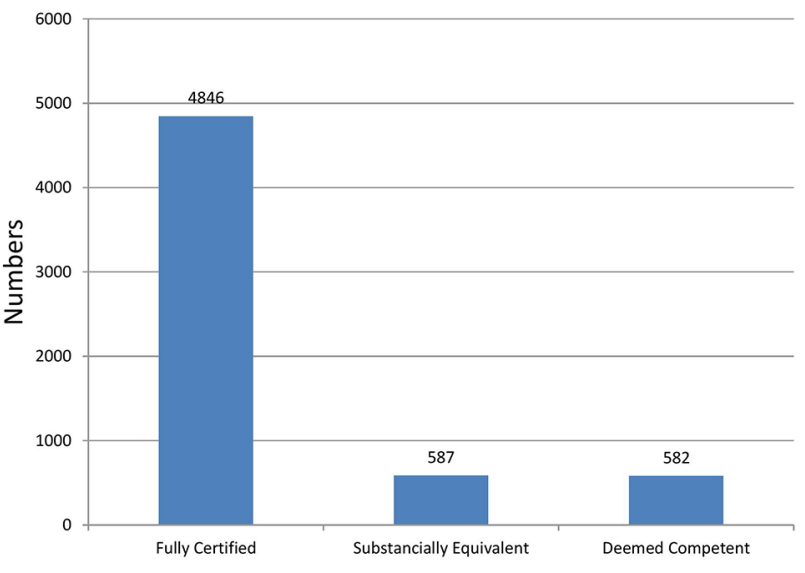

Figure 2 Certified healthcare aides working in continuing care in Alberta.

Around $81 \%$ of HCAs were fully certified, $9.5 \%$ were substantially equivalent and $9.5 \%$ were reported as deemed competent (figure 2). We did not find a statistically significant difference in certified HCAs between SL and LTC sites. Our finding showed that HCAs in SL

Table 2 HCAs utilisation in SL and LTC facilities $(n=115)$

\begin{tabular}{lllrr}
\hline Variables & LTC, $\mathbf{n}(\%)$ & $\mathbf{S L}, \mathbf{n}(\%)$ & \multicolumn{1}{c}{$\chi^{\mathbf{2}}$} & $\mathbf{p}$ Value \\
\hline Number of HCAs, mean (SD) & $73.9(61.2)$ & $31.4(27.2)$ & $4.6^{*}$ & $<0.01$ \\
Support resident with ADLs & $63(98.4)$ & $52(100.0)$ & 0.82 & 0.55 \\
Prepare meal & $4(6.3)$ & $20(38.5)$ & 18.1 & $<0.01$ \\
Housekeeping & $8(12.5)$ & $31(59.6)$ & 28.5 & $<0.01$ \\
Do laundry & $13(20.3)$ & $38(73.1)$ & 32.4 & $<0.01$ \\
Do charting & & & & \\
$\quad$ Tick charting & $58(90.6)$ & $42(80.8)$ & 2.3 & 0.10 \\
$\quad$ Resident charts & $40(62.5)$ & $47(90.4)$ & 11.9 & $<0.01$ \\
Assist with recreational activities & $38(59.4)$ & $36(69.2)$ & 1.2 & 0.18 \\
\hline Assist with therapy activities & $26(40.6)$ & $35(67.3)$ & 8.2 & $<0.01$ \\
\hline Do vital signs & $38(59.4)$ & $29(55.8)$ & 0.2 & 0.42
\end{tabular}

Medication assist

\begin{tabular}{|c|c|c|c|c|}
\hline Rectal suppositories & $57(89.1)$ & $27(71.8)$ & 20.8 & $<0.01$ \\
\hline Topical creams & $60(93.8)$ & $49(92.5)$ & 0.1 & 0.53 \\
\hline Inhaled medication & $4(6.3)$ & $42(79.2)$ & 64.7 & $<0.01$ \\
\hline Oral medication & $4(6.3)$ & $44(83.0)$ & 70.6 & $<0.01$ \\
\hline Rx eye/ear/nasal spray/drops & $12(18.8)$ & $43(81.1)$ & 45.3 & $<0.01$ \\
\hline Vaginally inserted medications & $1(1.6)$ & 19 (35.8) & 24.0 & $<0.01$ \\
\hline Application/removal of patches & $5(7.8)$ & $41(77.4)$ & 58.7 & $<0.01$ \\
\hline Consider HCAs fully used & $35(54.7)$ & $47(90.4)$ & 18.1 & $<0.01$ \\
\hline Mandatory medication assistance training & $24(50.0)$ & $43(86.0)$ & 14.7 & $<0.01$ \\
\hline HCAs paid to take training & $61(95.3)$ & $50(98.0)$ & 0.6 & 0.39 \\
\hline Concerns about residents' safety in current practice & $17(26.6)$ & $8(15.7)$ & 1.9 & 0.16 \\
\hline
\end{tabular}

*t-test statistics.

ADLs, activities of daily living; HCAs, healthcare aides; LTC, long-term care; SL, supportive living. 
facilities were more commonly involved in medication assistance processes with all types of medications, with the exception of rectal suppositories (table 2). The administration of rectal suppositories by HCAs was more common in LTC facilities. All other types of medications including inhaled medication, oral medication eye/ear/nose medication, vaginally inserted medication and application or removal of patches were much more commonly assisted by HCAs in SL facilities. We also found that HCAs do significantly more of the following tasks in SL compared to LTC (p value $<0.01$ ):

- Meal preparation (39\% vs $6 \%$ )

- Housekeeping (60\% vs $13 \%)$

- Laundry services (73\% vs $20 \%$ )

- Charting in resident charts $(90 \%$ vs $63 \%)$

- Assisting with therapy activities (67\% vs $41 \%)$

Survey respondents from SL facilities were significantly more likely to report that HCAs were fully used as compared to LTC facilities (90.6\% vs $54.7 \%$; $\chi^{2}=18.1$; p value $<0.01)$. A significantly larger proportion of survey respondents from SL facilities reported that medication assistance training was mandatory for their HCAs $(86 \%)$ compared to the LTC facilities $(50 \%) \quad\left(\chi^{2}=15.1\right.$; $\mathrm{p}$ value $<0.01)$. Slightly larger proportion of the survey respondents from LTC facilities were concerned about patient safety and adverse events related to their current medication management process than SL facilities (26\% vs $5 \%$ ); however, this difference was not statistically significant $\left(\chi^{2}=2.1 ; \mathrm{p}\right.$ value $\left.=0.11\right)$.

\section{DISCUSSION}

Our findings showed that there are significant variations in how HCAs are used in SL and LTC facilities. Broader utilisation of HCAs in SL raises the question whether they should also carry out similar responsibilities in LTC. The residents are more likely to be independent requiring very little support with activities of daily living in SL. In contrast, the substantial workload of HCAs includes direct resident care. ${ }^{9}$ Given that the residents are more complex in LTC, HCAs providing most of the direct care for activities of daily living is appropriate. However, HCAs are also trained and certified to provide assistance with medication, so they appear to be not using their full set of skills in LTC. For example, LPNs and RNs spend much of their time on medication delivery since residents receive high numbers of medications in LTC. Certified HCAs are trained in medication assistance and could help with routine medications to residents (as they regularly do in SL) thereby significantly supporting the regulated nursing providers. Currently, only a few LTC facilities involve HCAs in oral and other types of medication assistance. HCAs involvement in medication assistance would improve the utilisation of HCAs and maximise health human resources in LTC. ${ }^{16-19}$ HCAs involvement in medication assistance would also provide them the opportunity to use their skills. Walker ${ }^{20}$ argues that HCAs support in medication assistance would improve job satisfaction for all nursing staff. Another study reported that HCAs could safely assist with medication in LTC and they do not make higher medication errors than other professional nursing staff. ${ }^{21}$ The continuing care guidelines also suggest that licensed healthcare professionals may assign routine oral medication assistance tasks to HCAs where it is safe to do so. ${ }^{22}$ Involving HCAs in medication assistance could also improve compliance as residents have much more personal contact with HCAs than with other nursing staff and are more likely to accept medications from HCAs.

The findings from this study can be used to explore the HCAs involvement in medication assistance in other regions as the results are based on rich data from a large number of continuing care facilities. There will be challenges of integrating medication assistance into HCA activities in LTC. HCAs are already loaded with tasks related to resident care (dressing, feeding) and they omit tasks due to the lack of time resulting in missed care. ${ }^{23}$ Missed care can be any portion of required resident care omitted (in part or whole) or delayed, an error of omission. ${ }^{24}$ Errors of omission in continuing care are not limited to HCAs; for example, dose omission in LTC is the most common medication error by both HCAs and regulated healthcare professionals. ${ }^{21}$ Nevertheless, medication assistance is a time-consuming process and the workload of HCAs would significantly increase if they are assigned to medication assistance tasks. LTC facilities must consider hiring more HCAs to prevent any compromise on resident care if they plan to involve HCAs in medication assistance. The supply of HCAs should also be increased from training schools to meet the demand. In addition, we know little about the attitudes of HCAs toward change and their willingness to involve in medication assistance. Future studies should investigate the feasibilities of involving HCAs in medication assistance by exploring organisational and individual factors. Future studies may also investigate the impact of involving HCAs in broader care activities in LTC.

This study has a few limitations. First, we obtained a sample of 130 continuing care sites, and the non-responder sites could be different implying misrepresentation of typical HCA utilisation in continuing care in Alberta. Although the response rate of $41 \%$ was reasonable for this study, we speculate that the reason for not responding (for non-responders) could be their fear of changing practice as a result of participation in the study. Second, the survey was self-report which may have introduced bias in that we relied on the perception of the survey respondents.

In conclusion, the utilisation of HCAs appears to be greater at SL than LTC sites based on the range of HCA responsibilities in general and medication assistance in particular. The information is useful for other regions as well where HCAs constitute a major healthcare workforce. Given that there are differences in HCA utilisation between types of settings, not all HCA skills are translated into practice. From a workforce utilisation perspective, this implies unused resources for the healthcare system, 
loss of provider skills and knowledge, and fewer benefits to the residents. Standardising the roles and responsibilities of HCAs would optimise workforce utilisation in continuing care. ${ }^{16-19}$ The findings in this study are useful for the policy-makers to ensure the appropriate use of resources.

Acknowledgements The authors gratefully acknowledge the members of the advisory committee for their advice and constructive feedback throughout the project.

Contributors All authors were involved in planning the manuscript. PC coordinated the process. SD received the grant and conducted the study. MAA performed the data analysis and writing results. All authors contributed in writing the manuscript and approved the final version.

Funding The authors disclosed receipt of the following financial support for the research. This work was supported by Alberta Health (grant no 003760).

Disclaimer The views expressed in this publication are those of the authors and not necessarily those of the Alberta Health.

Competing interests None declared.

Ethics approval Ethical approval for this study was obtained from the Conjoint Health Research Ethics Board (REB 14-0377).

Provenance and peer review Not commissioned; externally peer reviewed.

Data sharing statement № additional data available.

Open Access This is an Open Access article distributed in accordance with the Creative Commons Attribution Non Commercial (CC BY-NC 4.0) license, which permits others to distribute, remix, adapt, build upon this work non-commercially, and license their derivative works on different terms, provided the original work is properly cited and the use is non-commercial. See: http://creativecommons.org/ licenses/by-nc/4.0/

(C) Article author(s) (or their employer(s) unless otherwise stated in the text of the article) 2017. All rights reserved. No commercial use is permitted unless otherwise expressly granted.

\section{REFERENCES}

1. Nelson S, Turnbull J, Bainbridge L, et al. Optimizing scopes of practice: new models for a new health care system. Ottawa, Ontario: canadian academy of Health Sciences, 2014. http://www.cahs-acss. ca/wp-content/uploads/2014/08/Optimizing-Scopes-of-Practice_ REPORT-English.pdf (accessed on 15 Feb 2017).

2. White D, Oelke ND, Besner J, et al. Nursing scope of practice: descriptions and challenges. Nurs Leadersh 2008;21:44-57.

3. Alberta Health Service (AHS). Clinical workforce strategic plan. 2011 2016 Appendix 8: Terms and definitions. Alberta, Canada: Health Professions Strategy \& Practice, March, AHS internal website. http:// insite.albertahealthservices.ca/hpsp/tms-hpsp-cwsp-appendices.pdf . (accessed 13 June 2016).

4. Alberta Continuing Care Association (ACCA) Workforce strategy for continuing care in Alberta 2012 to $2017 \mathrm{http}: / /$ www.ascha.com/PDF_ files/rollout/2013/ACCAWorkforceStrategyformatedMa72012.pdf (accessed 17 Feb 2017)
5. Strain LA, Maxwell CJ, Wanless D, et al; DAL) and long-term care (LTC) in Alberta: selected highlights from the Alberta Continuing Care epidemiological studies (ACCES. ACCES Research Group, University of Alberta: Edmonton AB, 2011.

6. Suter E, Deutschlander S, Makwarimba E, et al. Optimizing workforce utilization to inform care delivery in continuing care facilities. 2013. http://www.albertahealthservices.ca/assets/info/res/if-res-wreworkforce-utilization-continuing-care-report-2013.pdf (accessed 7th Dec 2016).

7. Cummings GG, Spiwek T, Hewko S, et al. Shining a light on the unregulated healthcare aide workforce: final report. 2013.http: //www.trec.ualberta.ca/en/ /media/trec/documents/reports/ finalalbertahealthreportshiningalight12.pdf (accessed on 7 Dec 2016).

8. Hewko SJ, Cooper SL, Huynh H, et al. Invisible no more: a scoping review of the health care aide workforce literature. BMC Nurs $2015 ; 14$.

9. Berta W, Laporte A, Deber R, et al. The evolving role of health care Aides in the long-term care and home and community care sectors in Canada. Hum Resour Health 2013;14:25.

10. Estabrooks CA, Squires JE, Carleton HL, et al. Who is looking after mom and Dad? unregulated workers in canadian long-term care homes. Can J Aging 2015;34:47-59.

11. Government A. Health care aide provincial curriculum: what is the curriculum. 2016. http://www.health.alberta.ca/documents/HCAides-Competency-2001.pdf (Accessed 13th Feb 2017).

12. Estabrooks CA, Squires JE, Hayduk L, et al. The influence of organizational context on best practice use by care Aides in residential long-term care settings. J Am Med Dir Assoc 2015;16:537.e1-537.e10.

13. Chou SC, Boldy DP, Lee AH. Measuring job satisfaction in residential aged care. Int J Qual Health Care 2002;14:49-54.

14. Pekkarinen L, Sinervo T, Perälä ML, et al. Work stressors and the quality of life in long-term care units. Gerontologist 2004;44:633-43.

15. Health A. Alberta's continuing care system. 2016. http://www.health alberta.ca/services/continuing-care-system.html (accessed on $7 \mathrm{Dec}$ 2016).

16. Stone R, Harahan MF. Improving the long-term care workforce serving older adults. Health Aff 2010;29:109-15.

17. Hussein S, Manthorpe J. An international review of the longterm care workforce: policies and shortages. J Aging Soc Policy 2015;17:75-94

18. Stone R. I, Dawson SL, Harahan MF. Why workforce development should be part of the long-term care quality debate. Alzheimer's Care Quarterly 2004;5:52-9.

19. Pan-Canadian Planning Committee on Unregulated Health Workers. Highlights of the 2009 pan-Canadian symposium . Maximizing health human resources: valuing unregulated health workers. http://www. cdnhomecare.ca/media.php?mid=2272 (accessed on 7 Dec 2016).

20. Walker MJ. Effects of the medication nursing assistant role on nurse job satisfaction and stress in long-term care. Nurs Adm Q 2008;32:296-300.

21. Arain M, Deutschlander S, Rostami M, et al. Should Health Care Aides assist with Medications in Long-Term Care? Gerontol Geriatr Med 2016;2.

22. Brandt K Alberta Health Services. Health Care Aide role in medication assistance. 2013. http://www.albertahealthservices.ca/ assets/info/seniors/if-sen-companion-to-map-hca-role-in-medassist.pdf (accessed on 22 Nov 2016).

23. Knopp-Sihota JA, Niehaus L, Squires JE, et al. Factors associated with rushed and missed resident care in western Canadian nursing homes: a cross-sectional survey of health care aides. J Clin Nurs 2015;24(19-20):2815-25.

24. Kalisch BJ, Landstrom GL, Hinshaw AS. Missed nursing care: a concept analysis. J Adv Nurs 2009;65:1509-17. 